\title{
A hybrid power generation system: solar-driven Rankine engine-hydrogen storage
}

\author{
Wen-Jei Yang*, Chuan-Hsien Kuo and Orhan Aydin ${ }^{\dagger}$ \\ Department of Mechanical Engineering and Applied Mechanics, University of Michigan, Ann Arbor, MI 48109, U.S.A
}

\begin{abstract}
SUMMARY
This paper reports on the feasibility of a hybrid power generation system consisting of a solar energy-driven Rankine engine and a hydrogen storage unit. Solar energy, the power for the hybrid system, is converted into electrical power through a combination of a solar collector, a tracking device to maintain proper orientation with the sun and a Rankine cycle engine driving an electrical power generator. Excess electricity is utilized to produce hydrogen for storage through electrolysis of water. At the solar down time, the stored hydrogen can be used to produce high-quality steam in an aphodid burner to operate a turbine and with a field modulated generator to supplement electric power. Case studies are carried out on the optimum configuration of the hybrid system satisfying the energy demand. A numerical example based on the actual measured solar input is also included to demonstrate the design potential. Copyright (C) 2001 John Wiley \& Sons, Ltd.
\end{abstract}

KEY WORDS: $\quad$ solar energy; Rankine engine; hydrogen storage; electric power generation

\section{INTRODUCTION}

Solar energy produces clean and virtually unlimited power. Facing the continuously increasing demand and the gradual depletion of the available fossil fuel reserve, it provides an attractive solution to the future energy needs. However, in most cases, it is not yet economically suitable as a major source for major energy needs. Researches are being conducted, both in large, megawatt scales and smaller domestic scales, to overcome the current problems in utilizing the solar energy efficiently.

Hybrid power systems integrate renewable energy technologies with some other forms of energy sources to provide power with good efficiency. The proper design and operation strategies of a hybrid system lead to the performance. Ashenayi and Ramakumar (1990) presented an approach to design an integrated renewable energy systems (IRES) based on the loss of powersupply probability (LPSP) as the key system parameter and minimization of the initial capital investment. Also, a computer program named IRES was developed for use as a design tool. A knowledge-based design approach that minimized the total capital cost at a pre-selected

\footnotetext{
* Correspondence to: Wen-Jei Yang, Department of Mechanical Engineering and Applied Mechanics, University of Michigan, Ann Arbor, MI 48109, U.S.A.

${ }^{\dagger}$ On leave from Mechanical Engineering Department, Karadeniz Technical University, 61080 Trabzon, Turkey.
} 
reliability level was presented by Ramakumar et al. (1992). The reliability level was quantified by the LPSP. The procedure included some resource-need matching based on economics, the quality of energy needed, and the characteristics of the resource. A detailed example was also presented and discussed to illustrate the usefulness of the design approach. In another article, Ramakumar et al. (1995) discussed some typical design scenarios and tile formulation of designs using the knowledge-based design tool IRES-KB with the aid of KAPPA(R)-PC development tools. A remote village with no electrical grid connection was chosen for the study since renewable systems were most likely to make their greatest impact in such locations. Yokoyama et al. (1994, 1997) presented a deterministic approach (1994) and a probabilistic approach (1997) to optimal unit sizing for hybrid power generation systems utilizing photovoltaic (PV) and wind energy. Device capabilities and electric contract demand were determined so as to minimize the annual total cost and annual energy consumption from the viewpoints of economy and energy saving or reduction in $\mathrm{NO}_{x}$ and $\mathrm{CO}_{2}$ emission, respectively. This optimization problem was considered as a multi-objective one, and a discrete set of Pareto optimal solutions was derived numerically by using the weighting method. Barley and Winn (1996) compared dispatch strategies using (1) an analysis of cost trade-off, (2) a simple, quasi-steady-state time-series model, and finally (3) HYBRID-2, a more sophisticated stochastic time-series model. An idealized predictive dispatch strategy, based on assumed perfect knowledge of future load and wind conditions, was developed and used as a benchmark in evaluating simple, non-predictive strategies. The results illustrated the nature of the optimal strategy, and indicated that one of two simple diesel dispatch strategies, either load-following or full power for a minimum run time, could be in conjunction with the frugal use of stored energy (the frugal discharge strategy). It could be virtually as cost effective as the ideal predictive strategy. The optimal choice of these two simple charging strategies was correlated to three dimensionless parameters, yielding a generalized dispatch design chart for an important class of systems. Modelling of hybrid power system, including the optimization of the dispatch strategy, was presented by Ashari and Nayar (1999). A computer program for a typical dispatch strategy was developed to predict the long-term energy performance and the lifecycle cost of the system. Peterson et al. (1999) reported on the operational experience acquired with a PV hybrid system installed as a line extension alternative at a residence located in northern New York State. The paper featured a detailed analysis of the energy flows through the system and quantified all losses caused by battery storage round-trip, rectifier and inverter conversions, and non-optimum operation of the generator and of the PV array. The paper also analysed the evolution of end-use electricity consumption since the installation of the PV hybrid system. A methodology was developed by Muselli et al. (1999) for calculating the correct size of a PV-hybrid system and for optimizing its management. The power for the hybrid system came from PV panels and an engine-generator, that is, a gasoline or diesel engine driving an electrical generator. Bonanno et al. (1999) developed a software package to evaluate the transient behaviours of hybrid systems during planning stage. In a recent paper, Yang and Aydin (2001) theoretically investigated a hybrid power system utilizing wind energy and hydrogen storage system, and identified its feasibility.

Solar energy can be collected by various types of solar collectors. There are two commonly used methods to turn solar energy into electricity. In the first method, a PV system directly turns the solar radiation into voltage difference in the panel material, which generates electrical currents. It has been widely used in various applications. Yet, a shortcoming of this kind of system is its high cost and extremely low efficiency. The second method is to turn the solar radiation energy into the increase in the sensible and latent heat of the circulating working fluid, which 
generates mechanical power output through the thermodynamic cycle process. Electricity is then generated from the mechanical power through the generator. This type of the energy conversion is called the solar-thermal process. For different types of application needs, different systems of collector, working fluid, and cycle types are used. In their works, Gurgenci (1986), Murthy and Murthy (1987), Gari et al. (1988) and Kuo et al. (1998) described design and analysis of several different types of solar-thermal systems.

There are several energy storage options (Andrews, 1976; Ramakumar, 1976; Swet, 1981) but hydrogen storage shows the most promise. Not only is hydrogen a 'clean energy source', but also it possesses high applicability. Hydrogen can be used as a fuel by itself or can be combined with organic materials to produce synthetic fuels (methane, methanol). It can be used in a fuel cell to generate electricity or can be burned with oxygen in water-cooled burner to produce high-quality steam, which in turn can drive a turbine-generator to generate electricity. Hydrogen production and storage represent the only readily available technology that can be reliably store renewable energy to supply the electricity and fuel customers of the 21 st century. Wind and solar power can seriously compete with all other sources only when the hourly, daily and seasonal variations can be effectively removed.

This study is aimed at identifying and modelling a hybrid system consisting of a solar energy-driven Rankine engine and hydrogen generation-storage cycle. An environmentally lowimpact organic working fluid, Dupont Suva ${ }^{\mathbb{R}}$ HCFC-123 is chosen for the Rankine cycle process, and parabolic trough-type solar collector is used to moderately concentrate the normal incident solar energy and boil the working fluid. The thermodynamic modelling of the hybrid system will be performed to build a comprehensive algorithm, which enables the process to be simulated as an aid to the design process. Actual solar energy data, collected both in summer and winter season, will be used in the simple simulation to evaluate the performance of the proposed system. With the results obtained, the feasibility of the system is discussed, and the key parameters effecting the system performance is clarified.

\section{GENERAL SYSTEM DESCRIPTION}

The schematic of the proposed solar powered-Rankine-based hybrid power generation system is shown in Figure 1. The system is consisted of two main parts. The first part is the solar collector-Rankine cycle power generation system described by Kuo et al. (1998). As shown in Figure 2, the solar radiation is trapped by the solar collector, and the energy is transferred to the working fluid circulating in the Rankine-based thermodynamic cycle. A turbine generates the mechanical power from the expansion of the working fluid. The second part is the hydrogen producing and storage system. In their paper, Yang and Aydin (2001) described how the excess energy from a wind-powered system can be stored by using the electrolysis process with the electricity from the wind turbine to produce hydrogen.

\section{SOLAR-RANKINE POWER GENERATION UNIT}

The $T-S$ (temperature vs. entropy) diagram describing the Rankine cycle process is shown in Figure 3, with numbers of the stages matching that of Figure 2. Normal incident solar radiation is collected by the parabolic trough collectors and concentrated on the collector absorber tubes. 


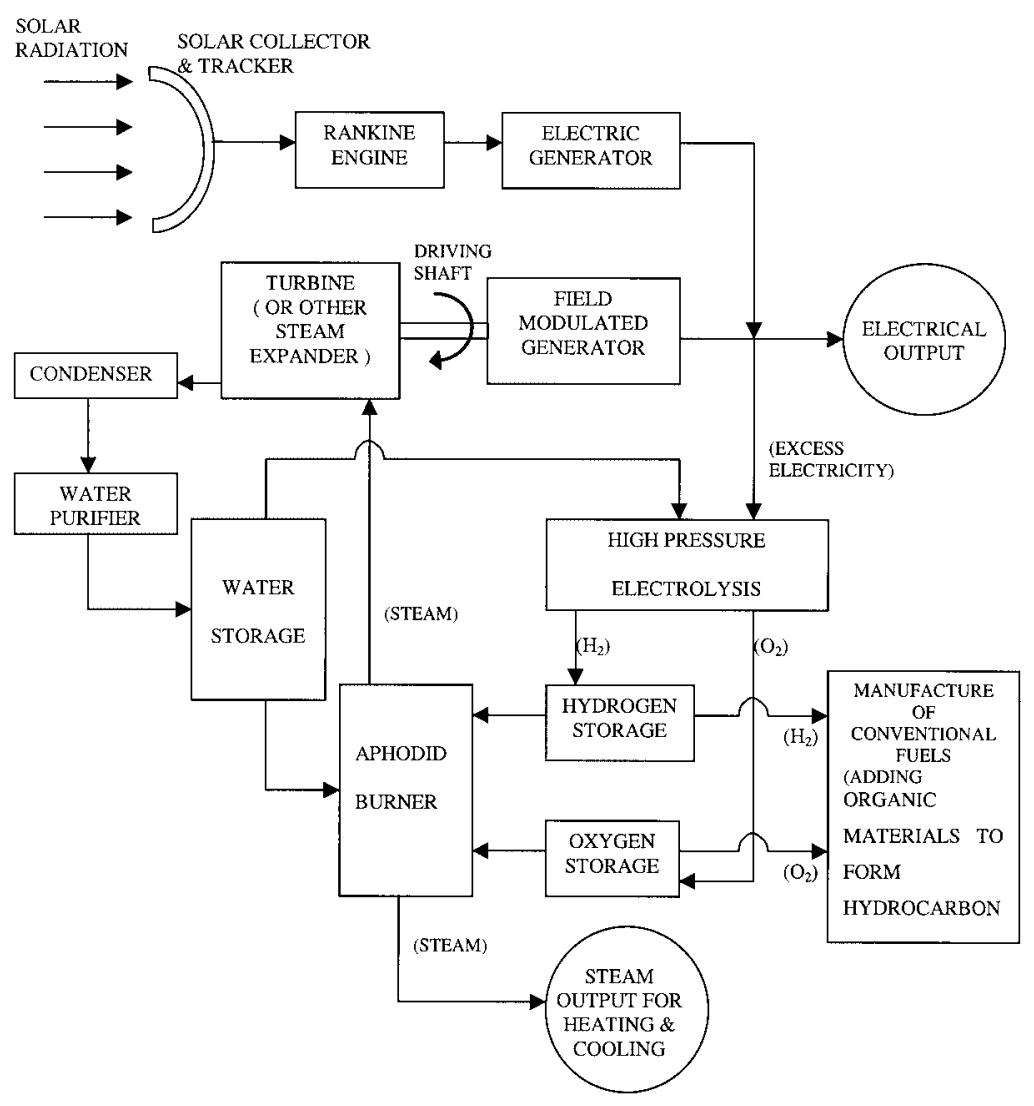

Figure 1. The design schematic of the proposed solar-Rankine/hydrogen-storage hybrid system.

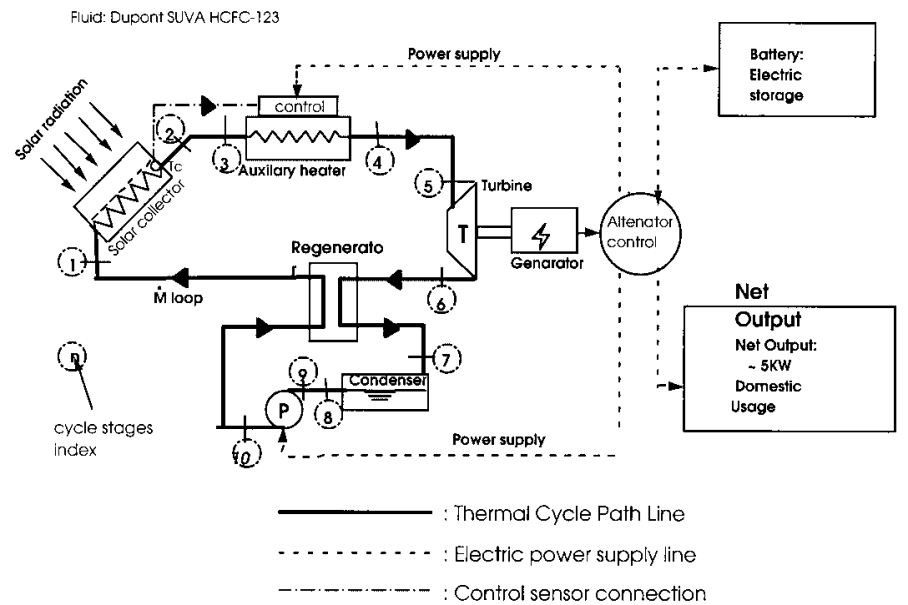

Figure 2. The schematic of the solar powered Rankine system for electricity generation. 


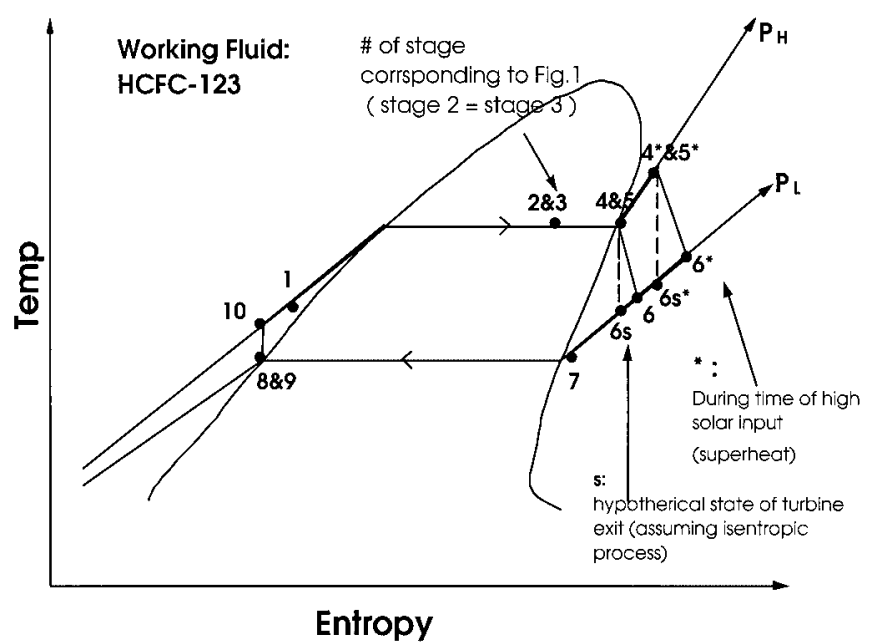

Figure 3. The $T-s$ diagram describing the solar-Rankine cycle used in power-generating system.

The working fluid, with the set flow rate $\dot{m}$ is evaporated while passing through the collector absorber tube (stages 1 and 2). An optional auxiliary heater is placed following the collectors (stages 3 and 4), powered by back up electricity or, in the current hybrid design, by the hydrogen burner. This heater, controlled by the collector outlet temperature, serves as the back up power source during temporary solar down time (such as cloud passing) to prevent the system from frequent stop, and as the working fluid temperature regulator during inoperative and start-up times. Mechanical power is produced by passing the working fluid vapour through a steam turbine (stages 5 and 6), which then drives a generator to produce electricity. The depressurized vapour is condensed in an air or water-cooled, constant pressure condenser (stages 7 and 8), and a circulation pump increases working fluid pressure to complete the working cycle (stages 8,9 and 1). An electricity power control unit directs and allocates the output electricity toward either the application usage or the hydrogen production system. The controller also turns on or off the pump and the heater according to the situation arising.

\subsection{General system control}

One major issue that all solar power systems face is that, the solar radiation is a highly transient, unstable energy source. There are many factors effecting the solar radiation input, including time, date, season, weather condition, location of the solar unit, and others. These factors necessitate methods to control the solar-based system completely different from the conventional fossil fuel power generation system.

For the proposed solar-Rankine hybrid system, the time transient solar radiation controls the system dynamics. Since the flow rate $\dot{m}$ is constant during operation, sometimes the excess solar radiation input would superheat the working fluid in the collector absorber tubes. And some other times, the solar radiation input is not sufficient to completely evaporate the working fluid to the saturated vapour state at the collector exit (stage 2). To avoid the wet vapour from entering the turbine, a control unit is recommended to shut off the circulation pump when the solar 
Table I. Technical data for a single module of Accurex type 3001 collector.

\begin{tabular}{lc}
\hline Aperture area & $5.58 \mathrm{~m}^{2}$ \\
Trough width & $1.83 \mathrm{~m}$ \\
Pylon length & $3.25 \mathrm{~m}$ \\
Absorber diameter & $32.8 \mathrm{~mm}$ \\
Glass tube diameter & $50 \mathrm{~mm}$ \\
Tube material & Steel \\
Coating & Black chrome \\
Reflector & $0.6 \mathrm{~mm}$ glass/steel laminate \\
Reflectivity & 0.92 \\
Tracking accuracy & $0.25^{\circ}$ \\
Weight* & $32.1 \mathrm{~kg} \mathrm{~m}{ }^{2}$ \\
$*$ Including reflector, & \\
$\quad$ support post and motor & \\
Survival wind constraint & $161 \mathrm{~km} \mathrm{hr}$ \\
\hline
\end{tabular}

radiation is not sufficient to completely evaporate the working fluid. The control unit is often connected to a temperature sensor in the collector or a pyrheliometer, and programmed to switch the circulation pump on and off, depending on the collector temperature readings or the direct normal solar radiation reading.

The optional auxiliary heater allows for the greater system flexibility while operating under different conditions. The control unit can be extended to integrate the auxiliary heater into the overall operating schemes. The control unit can be set to turn on the auxiliary heater during the temporary solar down time (such as cloud passing) to sustain continuous operations. Also, the heater can be used to regulate the temperature of the working fluid, and the turbine entrance conditions.

For the domestic scale solar Rankine systems, the simple, inexpensive and easy to maintain control system is strongly recommended over the more complicated systems, which may give better operating efficiencies, but are harder to install, operate and maintain, and are more expensive. The sophisticated control systems are more suitable for larger scale power generation systems.

\subsection{Parabolic trough collector}

The choice of solar collector for the domestic scale solar Rankine electricity generation unit is the line-focusing parabolic trough collector (PTC). There are a few reasons for this choice: First, with the moderate solar concentration ratio (40-80), PTC collectors enable the working fluids to achieve the higher evaporation and superheat pressures and temperatures $\left(>150^{\circ} \mathrm{C}\right)$ than that of the flat-plate collectors, thus increasing the Rankine cycle efficiencies. The point-focus-type collector is not considered because of its high installment and maintenance costs. Its extremely high concentration ratio $(>200)$ is not necessary for the scale of energy generation required by the investigated system. The parabolic trough collector is already a rather matured technology due to many years of designing and operating experience. Commercially available PTCs, with sun tracking capabilities, can be counted on to operate securely and efficiently. In this paper, the Acurex type 3001 collector, with design collecting efficiency of 58 per cent (Winter, 1991), is used for the system analysis. Other specifications of this collector unit are shown in Table I. 


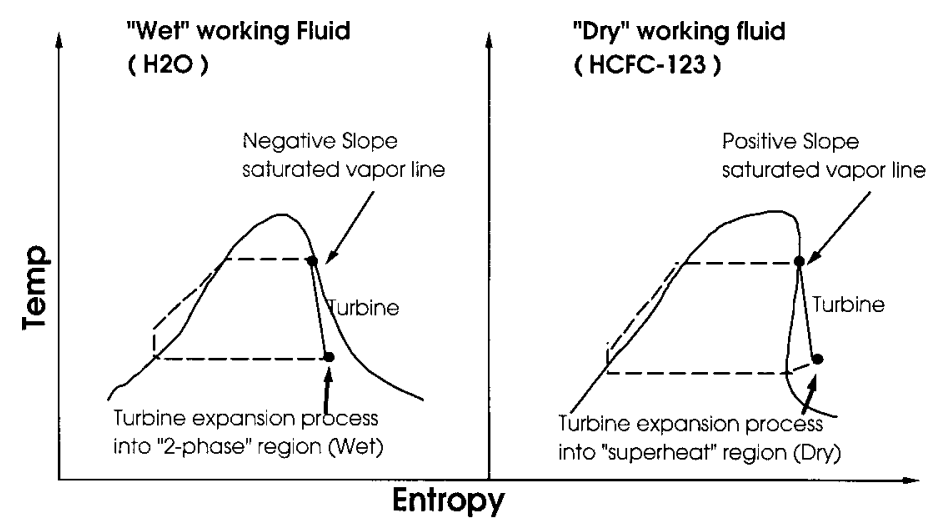

Figure 4. 'Wetting' and 'drying' working fluid in $T-s$ diagram.

\subsection{Organic working fluid}

The selection of the working fluids for the solar Rankine cycle system requires careful considerations. As described in Miller (1974) and Luchter (1967), a good working fluid should always be inexpensive, environmentally sound (low ozone depletion potential and global warming potential), chemically stable, non-toxic, and non-flammable. Furthermore, from thermodynamic considerations, the working fluids selected for this hybrid system preferably should also have the following characteristics (Abbin, 1977): (1) Moderate critical temperature not too much higher than the system operating temperature to enhance the heat transfer from absorber to the fluid. (2) Low specific vapour volume at condensing temperature to avoid large turbine blade and casing needs. (3) Small liquid-phase heat capacity to better improve the Rankine cycle to the Carnot cycle, which have the highest ideal cycle efficiency. (4) High molecular weight and density to allow the given mass flow rate to be achieved at lower turbine rotational speed and fewer stages. (5) The 'drying' characteristics, 'drying' type of working fluid is that with the positive slope for the saturated vapour line in the $T-S$ diagram. Figure 4 shows the 'drying' and 'wetting' characteristic of the working fluid in $T-s$ diagrams. 'drying' fluid ensures that the turbine exit is at the superheated region. This eliminates the erosion that damages the turbine blade, causing higher maintenance cost, and avoids decreasing efficiency due to 'wet' vapour in the turbine. Ideally, it is preferred to have the fluid exiting the turbine in saturated vapour form, instead of superheated state, to eliminate the condenser energy losses in superheat, and to lessen the condenser load. To resolve this, a regenerator can be added between turbine-condenser (stages 6 and 7) and pump-collector (stages 9 and 1) to recover some of this superheat energy otherwise lost in the condenser.

Realistically, it is difficult to have one working fluid that would satisfy all of the above criteria. Water is the most commonly used working fluid in the Rankine cycle power plants, and it has many advantages. Yet, in the domestic scale solar-Rankine application, water does not satisfy many of the preferred qualities described above, such as 'drying' characteristic and high molecular weight. After investigation, the organic working fluid is used because it does have many advantages in this solar-Rankine application (Wolpert and Riffat, 1996). In this study, HCFC123, a product of Dupont to replace the older environmentally unsound refrigerants such as R-11, 
$\mathrm{R}-114$, is chosen in this paper to be the working fluid for the proposed system. With molecular weight of 152.93 , atmosphere boiling point of $27.85^{\circ} \mathrm{C}$, critical temperature of $183.68^{\circ} \mathrm{C}$, good heat transfer properties, and relatively low price (Dupont Technical Information T-123-SI, 1996), HCFC-123 is an ideal choice for this application.

\section{THERMAL MODELLING AND SIMULATION OF THE SYSTEM}

From thermodynamic points of view, the designed domestic solar unit can be treated as a simple Rankine cycle with variable heat input. The methods for the analysis of the Rankine cycle are well documented in many thermodynamic texts. It is well known that the isentropic efficiencies of turbine and pump play an important role on the efficiency Rankine cycle. To evaluate the performance of the proposed system, computer modelling is proposed to account for the continuously changing solar conditions by decreasing the time steps of each calculation to avoid the use of long-term average data and simultaneously solving the whole cycle in an iterative process. A comprehensive computer simulation code is constructed to obtain the results of system output abilities from the given actual meteorological data. The flow chart shown in Figure 5 expresses the numerical process which simulates the operation of the designed solar system. The following sections describe in detail the thermodynamic analysis for each component of the system.

\subsection{Working fluid thermodynamic properties}

The computational simulation of the solar Rankine cycle requires the knowledge of values of various thermodynamic properties such as specific enthalpy $h$ and entropy $s$ for the chosen working fluid under different thermodynamic conditions ( $T$ 's and $P$ 's). The simulation program generates these values repeatedly during the duration of the simulation time period to account for the transient changes of the solar inputs and the subsequently changing conditions, especially in the superheated vapour region. To do so, the analytical equations of the thermal properties, formulated as the functions of the temperature and pressure (Dupont Technical Information T-123-SI, 1996), are applied in the algorithm. From the reference, the equation for the ideal gas constant pressure heat capacity for $\mathrm{HCFC}-123$ is

$$
\begin{gathered}
C_{\mathrm{p}}^{0}=c 1+c 2 T+c 3 T^{2} \\
c 1=28.9811 \\
c 2=0.304711 \\
c 3=-0.195477
\end{gathered}
$$

$C_{\mathrm{p}}^{0}\left(\mathrm{~J} \mathrm{~mol}^{-1} \mathrm{~K}\right)$ can be converted to $C_{\mathrm{p}}\left(\mathrm{J} \mathrm{kg}^{-1} \mathrm{~K}\right)$ with the known molecular weight. Having constant pressure specific heat as a function of temperature, vapour enthalpy along the isobaric line can be calculated from

$$
h(T, P)=h_{\mathrm{r}}\left(T_{\mathrm{r}}, P\right)+\int_{T_{\mathrm{r}}}^{T} C_{\mathrm{p}}(T) \mathrm{d} T
$$




\section{START}

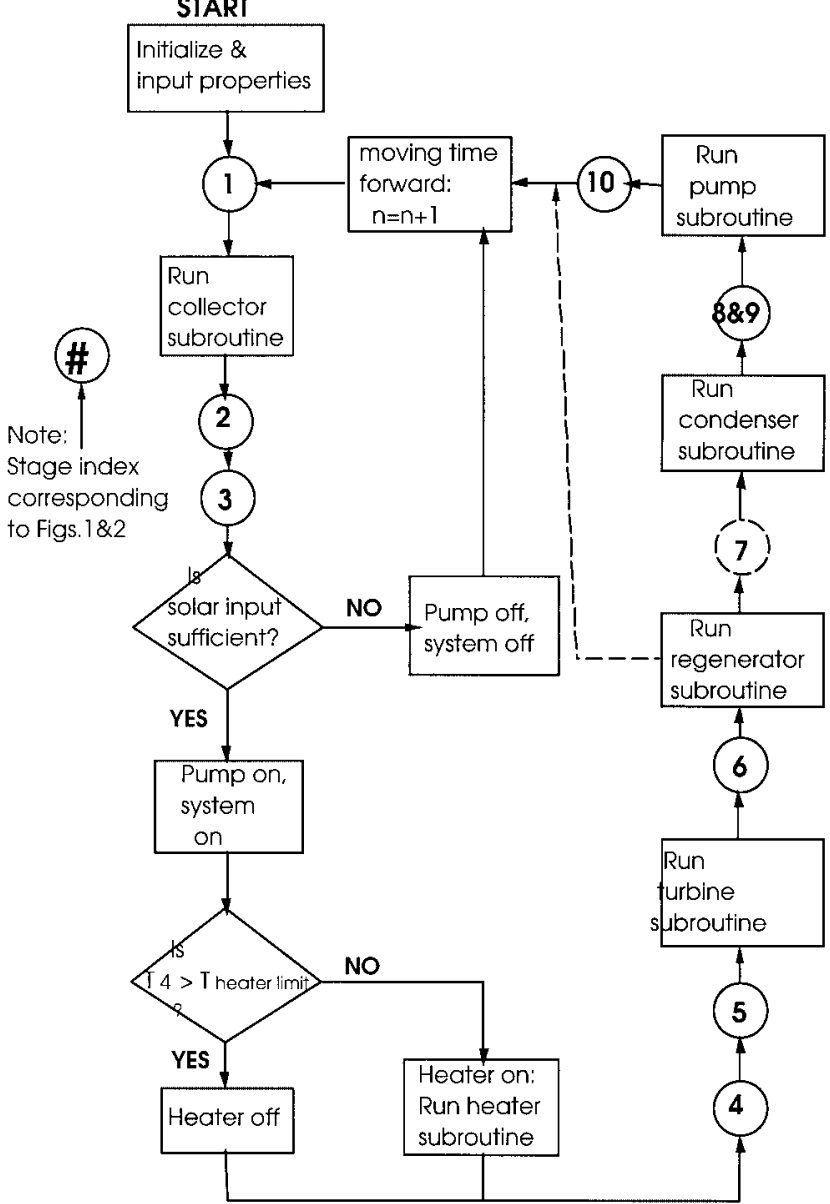

Figure 5. The flow chart of the simulation process for the designed domestic solar system.

where $h_{\mathrm{r}}$ is the reference enthalpy at the reference temperature $T_{\mathrm{r}}$ and pressure $P$ along the saturated vapour line. Also, vapour entropy is calculated using the following equation:

$$
s(T, P)=S_{\mathrm{r}}\left(T_{\mathrm{r}}, P\right)+\int_{T_{\mathrm{r}}}^{T} \frac{C_{\mathrm{p}}}{T} \mathrm{~d} T
$$

where $s_{\mathrm{r}}$ is the reference entropy.

From Equations (1)-(3), the enthalpy and entropy values of working fluid can be determined from the given vapour pressure and temperature. Applying the equations in reverse using Newton convergence method, the temperature of the working fluid vapour can also be found from the known entropy and enthalpy change. This gives the program the ability to manipulate the state values of the working fluid between system components. 


\subsection{Solar collector process (stages 1 and 2)}

The dynamics of the whole system is controlled by the time-varied amounts of solar radiation into the PTC collectors. In general, two major situations are encountered in the incident normal radiation collecting and the working fluid evaporating processes of the collector:

1. When the solar radiation is weak, it is not enough to sustain the continuous boiling of the working fluid to vapour. The pump is set off, while the received solar energy, after compensating the heat loss to environment is used to heat up the stationary working fluid in the collector tubes. The following equation is used for each time iteration step of the system simulation.

$$
h_{2}(n+1)=h_{1}(n)+\left[\mathrm{d} t\left(\frac{Q_{\mathrm{c}}(n)}{M_{\mathrm{c}}}\right)\right]-\left(\frac{Q_{\text {loss }}}{M_{\mathrm{c}}}\right)
$$

where $h$ is the specific enthalpy of the working fluid within the collector tube. Subscripts 1 and 2 beside the enthalpy $h$ depict the stage of the cycle corresponding to that of Figure 1. Here, $n$ is the time index in the iterative process of the system simulation. $\mathrm{d} t$ is the selected time step of the iteration. $Q_{\mathrm{c}}(n)$ is the energy input from solar collector during this time $n . M_{\mathrm{c}}$ is the mass of the working fluid contained in the collector tubes, and $Q_{\text {loss }}$ is the heat loss to the surrounding.

2. When the solar radiation is high, the collected radiation input can sustain the evaporation of working fluid at set flow rate, pump is turned on and the system continuously circulates to produce saturated or superheated vapour of working fluid. This is shown in the following equation:

$$
h_{2}(n+1)=h_{1}(n)+\left(\frac{\left(Q_{\mathrm{c}}(n)-Q_{\mathrm{loss}}(n)\right)}{\dot{m}}\right)
$$

where $\dot{m}$ is the set mass flow rate of the designed system when the circulation pump is turned on. If the value of $h_{2}$ is higher than the saturated vapour specific heat, the collector exiting vapour (stage 2) is in the superheated state.

The collector heat input into the working fluid, $Q_{\mathrm{c}}(n)$ and collector unit heat loss, $Q_{\text {loss }}(n)$ are calculated by the following equations:

$$
\begin{gathered}
Q_{\mathrm{c}}(n)=G_{\text {in }}(n) A \eta_{\mathrm{c}} \\
Q_{\text {loss }}(n)=A_{\mathrm{c}} h_{\text {loss }}\left(T_{\text {sat }, \mathrm{Ph}}-T_{\infty}(n)\right)
\end{gathered}
$$

where $G_{\text {in }}(n)$, and $T_{\infty}(n)$ are the incident normal solar radiation and the ambient temperature at time $n$, obtained from the collected meteorological data. $\eta_{\mathrm{c}}$ is the mean collector efficiency. $A$ and $A_{\mathrm{c}}$ are the collector collecting and tube areas, and $T_{\text {sat, } \mathrm{Ph}}$ is the saturate temperature of the working fluid at the Rankine cycle higher pressure.

\subsection{Other cycle stages}

After being evaporated in the collector tubes, the vapour of the working fluid passes through the turbine to generate mechanical power (stages 5 and 6). The saturated or superheated vapours expand and depressurize in the turbine blades. Vapour exits the turbine at the Rankine cycle lower pressure $P_{\mathrm{L}}$ and at lower temperature than that of the turbine entrance. 
For domestic scale, organic working fluid Rankine application, with the low pressure difference, the two or three stages reaction turbine is preferred for the application (El-Wakil, 1984). Turbine isentropic efficiency plays an important role in the overall cycle analysis, and it is usually determined experimentally. Equations characterizing the power generating process in the turbine will be shown in the following paragraphs.

Assume the vapour go through an isentropic (constant entropy) expansion process to a hypothetical state $6, s$

$$
s_{6, s}=s_{5}
$$

From Equation (10), and knowing the preset-fixed Rankine cycle lower operating pressure $P_{\mathrm{L}}$, entropy $s_{6, s}$ can be determined, and the specific enthalpy of this hypothetical stage $6, s, h_{6, s}$, can also be calculated. Then, actual state 6 and turbine power output $\operatorname{Pow}_{\mathrm{T}}$ at any time $n$ can be obtained from the following equations:

$$
\begin{gathered}
h_{6}(n)=h_{5}(n)+\eta_{\mathrm{T}}\left(h_{6, s}-h_{5}(n)\right) \\
\operatorname{Pow}_{\mathrm{T}}(n)=\dot{m}\left(h_{6, s}-h_{5}(n)\right) \eta_{\mathrm{T}}
\end{gathered}
$$

where $\eta_{\mathrm{T}}$ is the turbine isentropic efficiency determined by experimentation.

Exiting the turbine, the vapour of the working fluid goes through a constant pressure phase change process in the condenser to change into the state of saturated liquid, rejecting the latent heat into the environment or the condenser coolant (stages 7 and 8). The pressure of the working fluid within the condenser is equal to the Rankine cycle lower pressure $P_{\mathrm{L}}$, and the temperature is equal to the saturation temperature of the pressure $P_{\mathrm{L}}$. In the designed domestic scale system, the condenser unit can be connected to the water supply, as a heat exchanger, to provide water heating from the rejected heat. This will further improve the domestic energy efficiency.

The condenser load, $L_{\mathrm{c}}$, which is the rate of the latent heat rejection from condensing working fluid, can be calculated from the following equation:

$$
L_{\mathrm{c}}(n)=\dot{m}\left(h_{7}(n)-h_{\text {sat.liq }, P_{\mathrm{L}}}\right)
$$

where $h_{7}$ is the specific enthalpy of the vapour entering the condenser at time $n$, either from the turbine exit or the regenerator heat exchanger exit, if the regeneration is applied to the system, and $h_{\text {sat.liq, } P_{\mathrm{L}}}$ is the specific enthalpy of the saturated liquid at pressure $P_{\mathrm{L}}$, which is equal to $h_{8}$.

Circulation pump is the driving mechanism of the designed system. The saturated liquid of the working fluid leaving the condenser at low pressure $P_{\mathrm{L}}$ regains the pressure here to $P_{\mathrm{H}}$ by pumping (stages 9 and 10). The liquid is pumped back into the solar collector unit (stage 1) to complete the Rankine cycle process. The pump switch is linked to the control system, which, according to the solar condition, determines whether to turn on or off the pump. The pump is often powered by the stored electricity and the pump load, $L_{\mathrm{p}}$, is calculated by the following equation:

$$
L_{\mathrm{p}}=\dot{m}\left(\frac{v_{\text {sat.liq }}\left(P_{\mathrm{H}}-P_{\mathrm{L}}\right)}{\eta_{\mathrm{p}}}\right)
$$


where $v_{\text {sat.liq }}$ is the specific volume of the working fluid saturated liquid. And $\eta_{\mathrm{p}}$ is the pump efficiency. The specific enthalpy of fluid at pump exit, $h_{10}$, is

$$
h_{10}=h_{9}+\frac{L_{\mathrm{p}}}{\dot{m}}
$$

\subsection{Auxiliary heater (optional)}

The auxiliary heater (stages 3 and 4 ) and the accompanying control device give the designed solar power unit larger flexibility in the operation characteristics. For example, with a heater powered by oil or gas, the power generating unit becomes capable of continuous operation, even at the temporary solar down time. In the current design, the heater acts as a temperature regulator and short-term back up. It ensures that the working fluid is at the saturated vapour state before entering the turbine during the time of operation. Powered by the stored energy, the heater will not be turn on to keep the system running during the prolonged solar down time, such as nights and rainy days. Also, the heater will not be turn on during the time period of ample solar radiation input. Whenever the heater is off, it is obvious that

$$
h_{4}(n)=h_{3}(n)
$$

the enthalpy of the working fluid does not change through the auxiliary heater unit.

During the time when the heater is turned on to sustain the system operation, working fluid at state 4 is by design at the saturated vapour form, and enthalpy of state 4 is the saturated vapour enthalpy. The heat load of the heater, $L_{\mathbf{H}}(n)$, is calculated using the following equation:

$$
L_{\mathrm{H}}(n)=\frac{\left(\dot{m}\left(h_{\text {sat.vap, } P_{\mathrm{H}}}-h_{3}\right)\right)}{\eta_{\mathrm{H}}}
$$

where $h_{\mathrm{sat.vap}, P_{\mathrm{H}}}$ is the specific enthalpy of the saturated vapour at upper operation pressure, $h_{3}$ is the specific enthalpy of working fluid leaving the collector and entering the heater and $\eta_{\mathrm{H}}$ is the heater efficiency.

\subsection{Regenerator (optional)}

For the 'drying' type of organic working fluid, as shown in Figures 2 and 4, the working fluid tends to leave the turbine in the highly superheated state. In this case, much of this superheat energy would be wasted if the working fluid coming out of the turbine directly enter the condenser. A way to capture some of this energy is regeneration. As shown in Figure 2, a regenerator is suggested to be placed between stages 6,7 and 10,1. The regenerator works as a heat exchanger, transferred energy from excess superheat vapour at stages 6 and 7 to the subcooled liquid out of the pump. In an actual device, it could be a multi-pass shell and tube heat exchanger with the vapour passes through the shells and the liquid passes through the tubes. In thermal analysis, this process is illustrated by a temperature-length diagram for the counter-flow heat exchanger, shown in Figure 6. The rate of heat transferred through the regenerator at any time $n$ can then be calculated from the following equations based on the effectiveness-NTU 


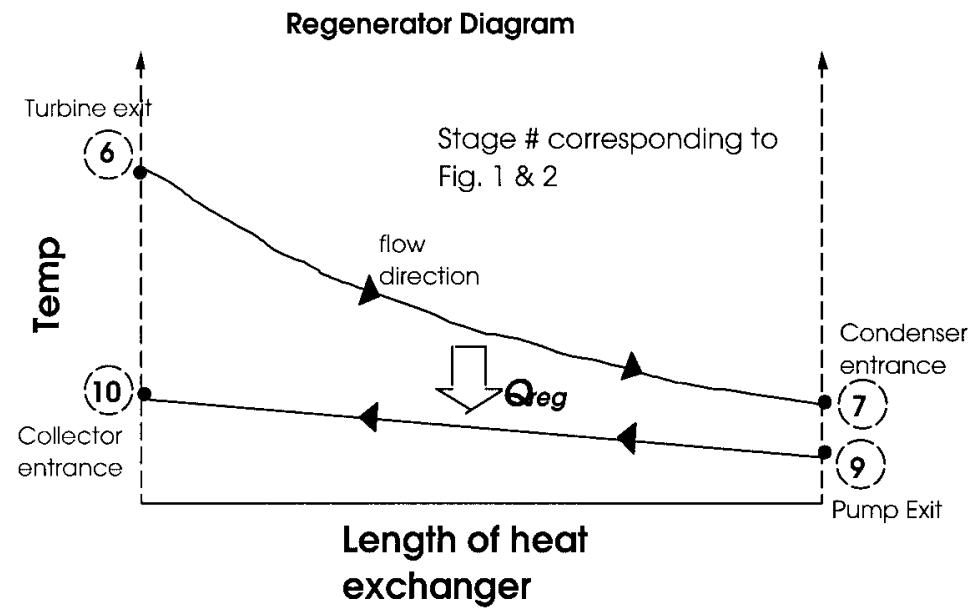

Figure 6. The regenerator heat exchanger diagram.

analysis

$$
Q_{\text {reg }}(n)=\eta_{\text {reg }} Q_{\max }(n)
$$

where $\eta_{\text {reg }}$ is the effectiveness of the heat exchanger. This value is obtained from experimental testing, and it is a function of the exchanger contact surface area, shape, and material. $Q_{\max }$ is the maximum amount of heat transfer, and it is calculated from

$$
Q_{\max }(n)=\dot{m} C_{\mathrm{p}_{\text {vap }}}\left(T_{6}(n)-T_{9}\right)
$$

where $C_{\mathrm{p}_{\text {vap }}}$ is the specific heat of the working fluid vapour. $T_{6}$ and $T_{9}$ are the fluid temperature at stages 6 and 9.

\subsection{Electricity generator}

An induction generator connected to the rotating shaft of the turbine generates the electricity. This is a straightforward process in which the electrical power generated at time $n, L_{\text {elec }}$ is simply

$$
\operatorname{Pow}_{\text {elec }}(n)=\eta_{\mathrm{g}} \operatorname{Pow}_{\mathrm{T}}(n)
$$

where $\eta_{\mathrm{g}}$ is the generator efficiency. The electricity generated is diverted either for the household usage, storage, or running system components such as pump and solar collector tracking motors.

\subsection{System modelling summary}

Using the previously described thermal modelling schemes, a comprehensive computational scheme applying all of the above component analysis is constructed. The time-varying properties of available solar energy present some challenges in converging the working fluid properties. The employed control scheme also affects the program flow of the computational process. Especially, 
the addition of regenerator and auxiliary heaters further complicate the analysis. Various assumptions and simplifications, such as constant subcooled liquid density, and constant component efficiencies are made to decrease the complexity of the computational procedure. Yet, the current goal of the system modelling performed gives a good estimate of the system power generation performance, and describes the dynamics between the system components and applied thermal conditions.

\section{SIMPLE RANKINE SYSTEM SIMULATION}

Simple, limited system simulation can give a rough estimate of the power generating performance of the proposed domestic scale solar-Rankine system (Kuo et al., 1998). Using the meteorological data taken in 1984, in the hourly bases, of the normal incident solar radiation and ambient temperature by the Space Physics Research Laboratory at University of Michigan, provided by Professor Dennis Baker, the solar Rankine power generation system is analysed to calculate the electricity production performance under the following conditions:

HCFC-123 working fluid mass flow rate, $\dot{m}: 0.05 \mathrm{~kg} \mathrm{~s}^{-1}$.

Number of PTC collector units: 4.

Total collecting area, $A=22.32 \mathrm{~m}^{2}$.

Collector fluid mass, $M_{\mathrm{c}}: 15.2 \mathrm{~kg}$.

Total absorber pipe area, $A_{\mathrm{c}}: 1.323 \mathrm{~m}^{2}$.

Collector net heat transfer coefficient, $h_{\text {loss }}: 1 \mathrm{~W} \mathrm{~m}^{-2} \mathrm{~K}$.

Upper pressure, $P_{\mathrm{H}}: 1000 \mathrm{kpa}(\sim 10 \mathrm{~atm})$.

Lower pressure, $P_{\mathrm{L}}: 110 \mathrm{kpa}$.

Temperature limit to turn pump on: saturation temperature at upper pressure.

Temperature limit for heater switch on: saturation temperature at lower pressure.

Pump efficiency, $\eta_{p}: 85$ per cent.

Turbine efficiency, $\eta_{t}: 85$ per cent.

Generator efficiency, $\eta_{g}: 80$ per cent.

The number of the solar collectors and the working fluid flow rate used in the simple simulation are chosen after considerations in feasibility for domestic scale usage. In actual applications, they can be changed according to the output needs. The efficiencies for the components used are chosen within the range of the commonly available commercial designs, that are also often been used in the common thermodynamic text books while dealing with general components efficiencies (Van Wylen et al., 1994).

The solar radiation and the ambient temperature data are processed to be presented in a hourly average form. In this case, calculations for the radiation input, electricity generation output, and other related properties are all lumped into hourly average values.

Figures 7 and 8 show the hourly average normal incident radiation and the hourly net output electricity, simulating the daily operations for the days of $1 / 15$ and $7 / 16$ of 1984 . Weather condition for $1 / 15$ shows a sunny and cold winter day, while $7 / 16$ is a hot summer day, partly cloudy in the late morning hours.

Hourly net system electricity outputs vary closely with the hourly normal incident radiation. This is expected because of the absence of the thermal energy storage device for a simple system. The system is very sensitive to the changes in solar input condition. 


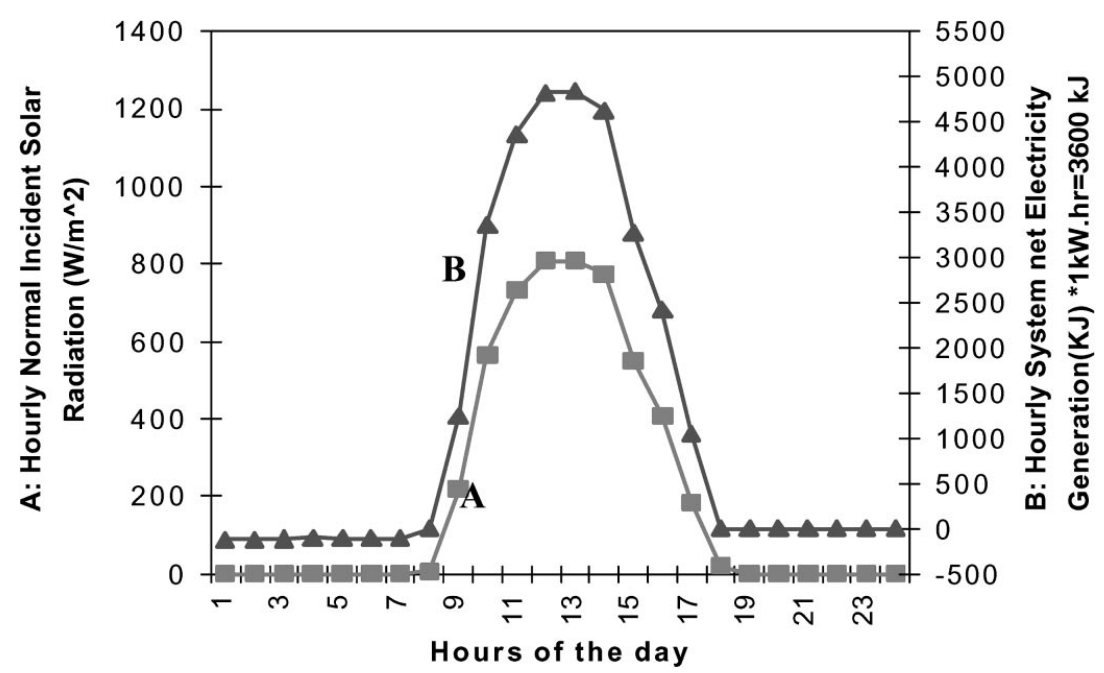

Figure 7. (A) Hourly normal incident solar radiation and (B) hourly net electricity generation for the date of $1 / 15,1984$.

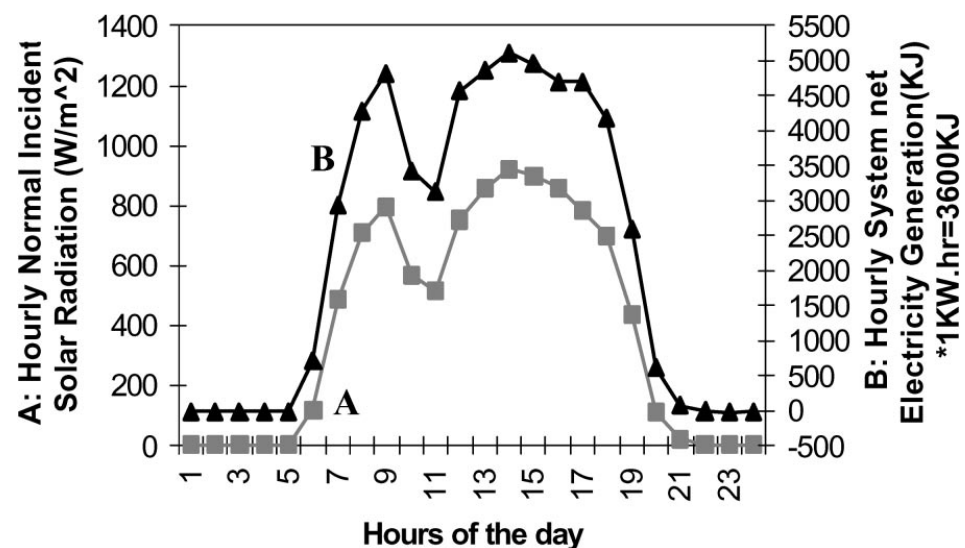

Figure 8. (A) Hourly normal incident solar radiation and (B) hourly net electricity generation for the date of $7 / 16,1984$.

The net electricity generation is $7.886 \mathrm{kWh}(28389.756 \mathrm{~kJ})$ for $1 / 15$, and $15.41 \mathrm{kWh}$ $(55489.673 \mathrm{~kJ})$ for $7 / 16$. For the daily average electricity usage of $25 \mathrm{~kW} \mathrm{~h}$, the system provided 31.54 and 61.66 per cent of the daily demands. The reason this substantial difference in resulting output between a summer and a winter day is apparent, concerning the fact that for the latitude of 42.42 of University of Michigan, the difference between the daily sun shine times, solar radiation intensity, and ambient temperature varies largely between seasons. The daily total normal incident radiation for $1 / 15$ is $113.53 \mathrm{~kW} \mathrm{~h}$, giving the cycle efficiency of 14.47 per cent and total 


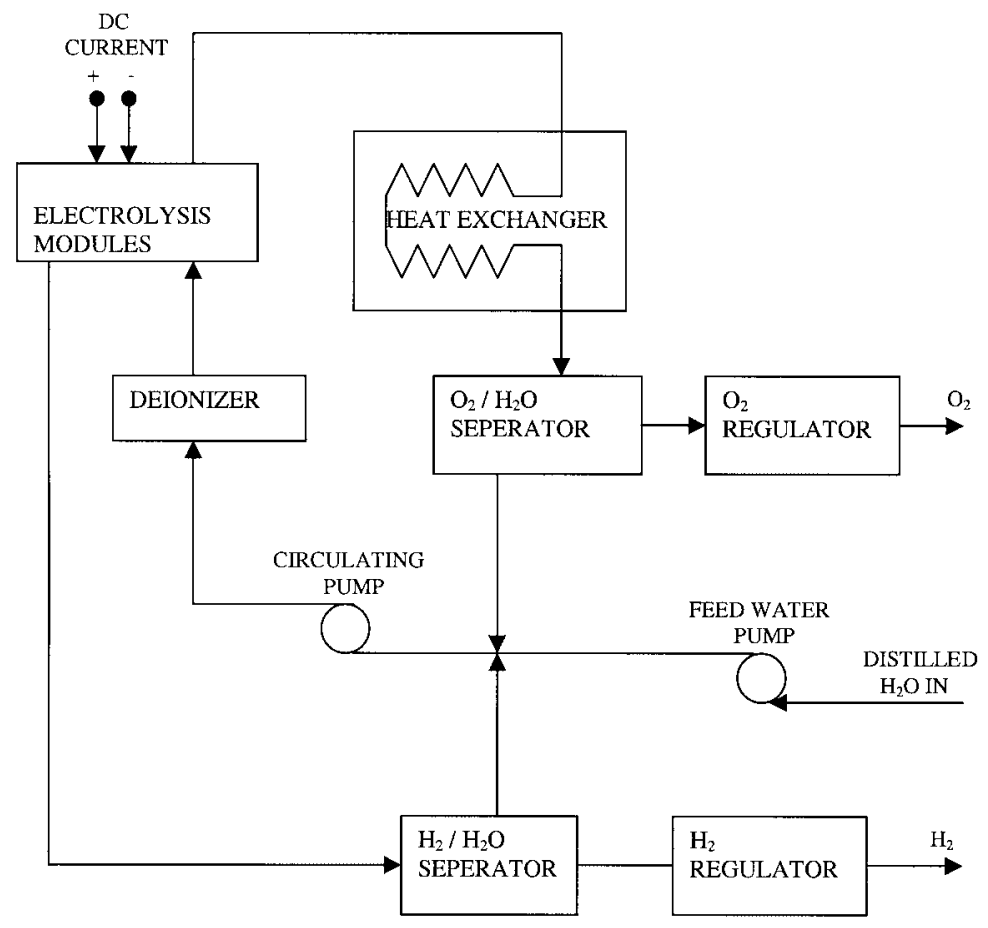

Figure 9. Electrolytic hydrogen generation system.

system efficiency of 6.946 per cent. For $7 / 16$, the total radiation is $212.86 \mathrm{~kW} \mathrm{~h}$, thus giving the cycle efficiency of 15.08 per cent and overall system efficiency of 7.24 per cent. Under this system setup condition, during the solar peak time on $7 / 16$, the normal solar radiation is high enough for the working fluid to be superheated. This superheating increases the Rankine cycle efficiency slightly.

\section{HYDROGEN STORAGE/CONVERSION SYSTEM}

Hydrogen is a clean, storable, and transportable fuel. It is abundantly available from sunlight and water. As a storage medium, it offers a great advantage with its infinitely long shelf life. Despite its low energy density compared to other storable fuels, it is justifiable to use because of its clean, environmentally friendly combustion, and mature transportation and storage techniques. The process that produces hydrogen from the water is called electrolysis. Figure 9 shows a schematic of a typical electrolytic hydrogen generation plant. When the load demand is less than the output of the generator in Figure 1, the excess DC power is relayed to the electrolytic cell where it is used to electrolyse the de-ionized water. The electrolytic process of decomposing water into hydrogen and oxygen is the reverse of hydrogen combustion or

$$
2 \mathrm{H}_{2} \mathrm{O} \rightarrow 2 \mathrm{H}_{2}+\mathrm{O}_{2}
$$


where, ideally, $39.3 \mathrm{kWh}$ of energy input is needed per kilogram of hydrogen gas produced. In their paper, Yang and Aydin (2001) investigated comprehensively various issues effecting the efficiency of the hydrogen production. It was concluded that it is most efficient to operate the cell at intermediate temperatures and elevated pressure.

Hydrogen can be stored as hydrogen compressed gas or liquid. However, when stored as a liquid, hydrogen loses much energy due to the liquefaction process. Therefore, storage of hydrogen as compressed gas offers the best option. The simulation of a single-stage reciprocating compressor and the determination of the corresponding compressor power requirement are omitted here.

\section{SIMPLE PERFORMANCE EVALUATION}

From the result of the earlier Rankine cycle power generation simulation, at a typical summer day in July, a system with only four solar collectors can accommodate about two third of the electricity requirement of a typical household. When an expansion to a larger system with twice the number of the collectors and subsequently doubling the working fluid flow rate is considered, it is apparent that the electricity output of such a unit will exceed the requirements. An estimate of the excess electricity power is $5.82 \mathrm{~kW} \mathrm{~h}$ in a typical summer day for the eight-collector Rankine system. From the analysis of Yang and Aydin (2001), where the efficiency of electrolysis process is estimated to be about 95 per cent, an amount of $0.14 \mathrm{~kg}$ of hydrogen can be produced and stored for further usage. Of course, the production of hydrogen is closely related to the size of the hybrid units, which can be determined based on the operational requirements.

\section{CONCLUDING REMARKS}

In this paper, solar energy-hydrogen storage hybrid power generation system has been thoroughly investigated and analysed. The solar radiation energy drives a Rankine engine, which then drives an electrical power generator. Excess electricity is diverted into electrolysis cell to produce hydrogen for storage. The hydrogen stored in a pressurized vessel can be used as fuel. When the hydrogen and the oxygen are burned in an aphodid burner, beside heating power, steam with good quality is produced which is ideal for usage in space heating, or driving a steam turbine to produce electrical power at solar down time. This co-operation of solar and hydrogen power is the essence of the proposed hybrid system. A general analysis of the system gives credence to the feasibility of such a system. In addition, this system also works effectively when wind is used as the driving power to produce electricity. Finally, the most important aspect of the solar energyhydrogen storage system is that it produces no harmful waste and depletes no resources. In the current environmentally conscious state of mind, the advantages of this system are greatly apparent.

\section{NOMENCLATURE}

$\begin{array}{ll}A & =\text { collector collecting area }\left(\mathrm{m}^{2}\right) \\ A_{\mathrm{c}} & =\text { collector tube area }\left(\mathrm{m}^{2}\right)\end{array}$

Copyright (C) 2001 John Wiley \& Sons, Ltd.

Int. J. Energy Res. 2001; 25:1107-1125 


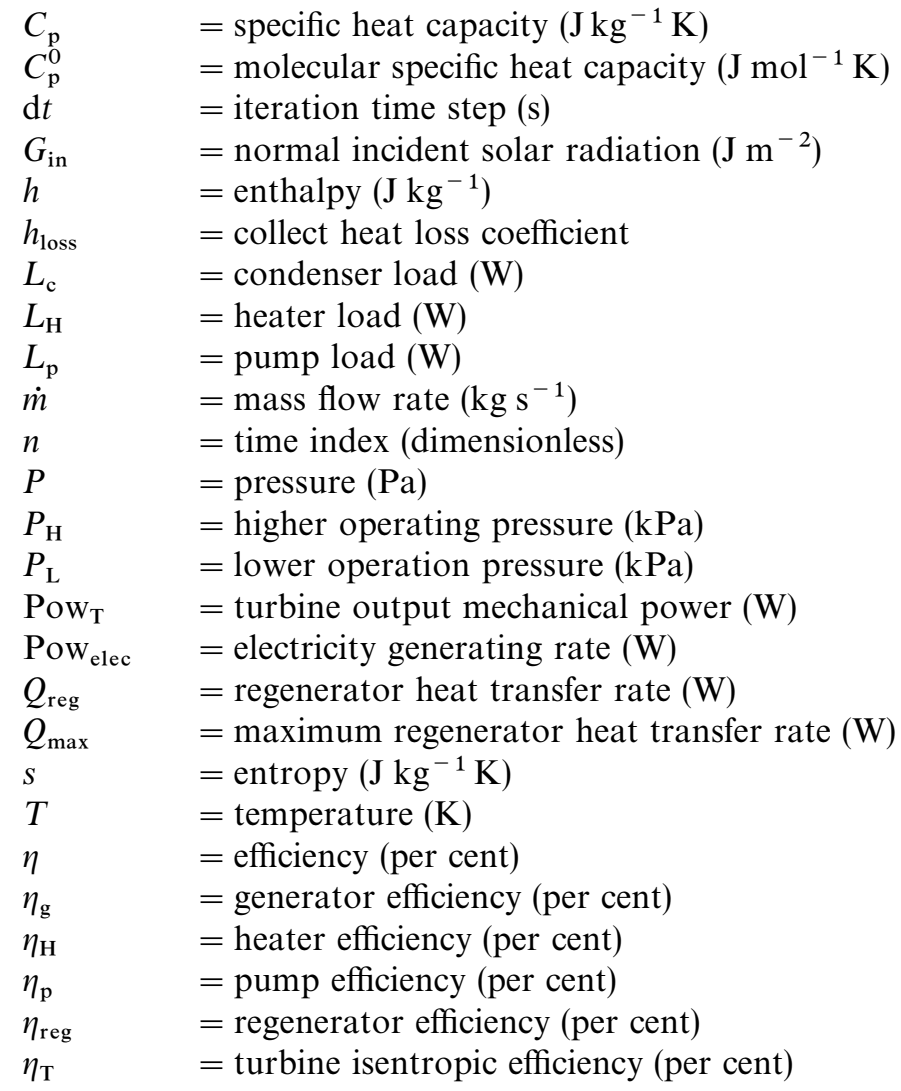

\section{REFERENCES}

Abbin JP. 1977. Program CYCLE-A Rankine cycle analysis routine, SAND74-0099. Sandia National Laboratories, Albuquerque, NM.

Andrews JW. 1976. Energy-storage requirements reduced in coupled wind-solar generating systems. Solar Energy 18(1):73-74.

Ashari M, Nayar CV. 1999. An optimum dispatch strategy using set points for a photovoltaic (PV)-diesel-battery hybrid power system. Solar Energy 66(1):1-9.

Ashenayi K, Ramakumar R. 1990. IRES-A program to design integrated renewable energy systems. Energy 15(12):1143-1152.

Barley CD, Winn CB. 1996. Optimal dispatch strategy in remote hybrid power systems. Solar Energy 58(4-6):165-179.

Bonanno F, Consoli A, Raciti A, Morgana B, Nocera U. 1999. Transient analysis of integrated diesel-wind-photovoltaic generation system. IEEE Transactions Energy Conversion 14(2):232-238.

El-Wakil MW. 1984. PowerPoint Technology, McGraw-Hill: New York.

Gari H, Khalifa A, Radhwan A. 1988. Design and simulation of a solar-powered/fuel-assisted Rankine engine for power generation. Applied Energy 30:245-260.

Gurgenci H. 1986. Performance of power plants with organic Rankine cycles under part-load and off-design conditions. Solar Energy 36(1):45-51.

Kuo CH, Yang WJ, Arai N, Mori K. 1998. Solar-powered organic Rankine system for domestic electric-power generation. Energy and the Environment, Proceedings of the Second Trabzon International Energy and Environment Symposium:67-74.

Luchter S. 1967. A quantitative methods of screening working fluids for Rankine cycle power plants. ASME paper 67-GT-12. 
Miller DR. 1974. Rankine cycle working fluids for solar-to-electrical energy conversion. Monsanto Research Corporation, MRC-SL-399, Final Report for Sandia Laboratories, Contract 58-5556.

Murthy SS, Murthy MVK. 1987. Experimental studies on a solar thermal power plant. Applied Energy 27:305-319.

Muselli M, Notton G, Louche A. 1999. Design of hybrid-photovoltaic power generator, with optimization of energy management. Solar Energy 65(3):143-157.

Peterson AJ, Perez R, Bailey B, Elsholz K. 1999. Operational experience of a residential photovoltaic hybrid system. Solar Energy 65(4):227-235.

Ramakumar R. 1976. An assessment of hydrogen as a means to store solar energy. Proceedings of the Sharing the Sun! Solar Technology in the Seventies Conference, Winnepeg, Canada, The American Section of the Int. Solar Energy Society, 8:163-175.

Ramakumar R, Abouzahr I, Ashenayi K. 1992. A knowledge-based approach to the design of integrated renewable energy-systems. IEEE Transactions on Energy Conversion 7(4):648-659.

Ramakumar R, Abouzahr I, Krishnan K, Ashenayi, K. 1995. Design scenarios for integrated renewable energy systems. IEEE Transaction Energy Conversion 10(4):736-746.

Swet CJ. 1981. Energy storage for solar applications. In Solar Energy Handbook, Kreider JF, Kreith F (eds), McGraw-Hill: New York.

Van Wylen G, Sonntag R, Borgnakke, C. 1994. Fundamentals of Classical Thermodynamics. Wiley: New York.

Winter CJ. 1991. Solar Power Plants. Springer: New York.

Wolpert JL, Riffat SB. 1996. Solar-powered Rankine system for domestic applications. Applied Thermal Energy 16(4):281-289.

Yang WJ, Aydin O. 2001. Wind energy-hydrogen storage hybrid power generation. International Journal of Energy Research 25(5):449-463.

Yokoyama R, Ito K, Yuasa Y. 1994. Multiobjective optimal unit sizing of hybrid power generation systems utilizing photovoltaic and wind energy. Journal of Solar Energy Engineering 116(4):167-174.

Yokoyama R, Ito K, Sakashita M, Matsumoto Y, Yuasa Y. 1997. Multiobjective optimal unit sizing of grid-connected photovoltaic system in consideration of its probabilistic characteristics. Journal of Solar Energy Engineering 119(2):134-140 